\title{
Futurology in the College Classroom
}

\author{
Skylar Davidson, MA \\ PhD Candidate, Department of Sociology \\ University of Massachusetts Amherst
}

There is little research on teaching futurology, which is surprising, given that instructors with a future-oriented perspective can encourage students to express constructive hope about controversial problems (e.g., climate change) rather than denying problems (Ojala, 2015). This study evaluates what learning outcomes can be accomplished through three different future-oriented in-class group activities: a future-oriented discussion, a future-oriented roleplay activity, and a backcasting activity. Analysis of student feedback suggests that these three activities encourage similar levels of student interest, understanding, and productive discussion while helping students practice both general college skills and skills specifically

related to futurology. The main strength of future-oriented discussion is general understanding of both a topic and one's own perspective on it; of future-oriented roleplay, debate and emotional engagement; and of backcasting, evaluation of different potential futures and a sense of ownership over the future.

Futurology is the process of forecasting or designing the future (Serra Del Pino, 1998), and futurology encompasses the short-range, mid-range, and long-range future. There is little research on teaching futurology, which is surprising, given that instructors with a future-oriented perspective can encourage students to express constructive hope about controversial social problems (e.g., climate change) rather than denying problems (Ojala, 2015). Future-oriented education is important for all instructors, not only those in the discipline of futurology, because it helps everyone learn how to live in a complex and rapidly changing society (Masini, 2011). Helping students develop a future-oriented perspective allows them to manage the uncertainty of the future logically, not only in academic settings but also in work and in everyday life (Masini, 2011). There are different ways to incorporate futurology into college classes, and because these methods require students' active participation during class, they further the active learning approach that has been demonstrated to benefit students more than traditional lecture-based classes (Eglitis, Buntman, \& Alexander, 2016; Roehl, Reddy, \& Shannon, 2013).

By explaining three different kinds of futurology activities - future-oriented discussion, future-oriented roleplay, and backcasting - and with the evaluation of the learning outcomes these activities can accomplish, my study responds to the need to evaluate how instructors can enhance student engagement during active learning (Witkowski \& Cornell, 2015) and contributes to instructors' understanding of how to effectively incorporate futurology into postsecondary education. The structure of my article is as follows: background information on active learning activities; an overview of my study method, as well as detailed descriptions of the three activities I studied; and a discussion of the results of the study. 


\section{Background}

One method of incorporating futurology into college classes is discussion. Modern students sometimes report that discussion is more valuable to them than lecture in that it helps them pay attention more easily, it helps them feel accountable for logical thinking, and it allows them to hear diverse viewpoints (Roehling, Kooi, Dykema, Quisenberry, \& Vandlen, 2010). Class discussion can spark interest in a subject, and it can create a space to dispel misconceptions about course content as long as the facilitator provides an environment of openness and respect (Tran, Weigel, \& Richmond, 2014). Therefore, a future-oriented discussion can encourage students' interest in considering diverse future trajectories and evaluating them logically.

Discussion has been shown to increase the likelihood that students come up with valid answers to questions even if no one in a discussion group knew the answer at the beginning of the discussion (Smith et al., 2009). In other words, students who do not know an answer can engage in productive discussion to find an answer through talking through problems logically (Smith et al., 2009). Following from this, discussion is particularly useful when engaging with futurology in a class, because no one knows the future, but people can collectively build reasonable suggestions for future actions.

Some other methods of incorporating futurology into college teaching are future-oriented roleplay and backcasting (determining a desirable future situation at a particular point in the future and working backward to think about what would need to happen between the present and the stated future time in order for that future situation to come about). While a major strength of discussion is its ability to encourage reflection (Roehling et al., 2010), roleplaying and backcasting are more solutionoriented; they provide the ability for a clear conclusion through a vote (in a roleplay) or a plan of action (in a backcasting activity).

Though much prior research on roleplay has focused on current events or historical events (e.g., Carnes, 2014; Simpson \& Elias, 2011), roleplay can also be futureoriented. Educational theorists throughout the centuries have used roleplay as a method of encouraging students to engage with scholarly texts and complex ideas (Carnes, 2014). In college, professors sometimes treat roleplay skeptically, as if it were only entertainment (Carnes, 2014; Favila, 2015); however, evidence-based studies of roleplay have generally found it to improve students' communication skills and understanding of course content (Carnes, 2014; Lightcap, 2009).

College-level roleplay can range in scope from small activities that make up part of a single class period to large-scale games spanning several weeks, such as Reacting to the Past, a type of roleplay in which students take on the roles of historical figures during particular turning points in history such as the French Revolution and engage in reading, debating, and strategizing both in and out of class (Carnes, 2014). Regardless of scope, roleplay activities often help students engage with course material and with each other. Roleplay can increase students' emotional engagement, as demonstrated with students in Reacting to the Past classes reporting excitement, eagerness to attend class, and understanding of the feelings that accompanied historical events (Carnes, 2014; Houle, 2006). Thinking of potential future problems such as war, racism, and environmental degradation often elicits emotional reactions from students, both positive and negative, as they think about the need to solve these 
problems; instructors can use roleplay to help students manage emotions constructively (Lloyd \& Wallace, 2004; Miller, 2014). Effective college-level roleplay encourages students to feel as if their range of thought has been expanded rather than artificially limited by the range specified in the activity guidelines (Ching, 2014; Simpson \& Elias, 2011).

Backcasting is another futurology technique that can be used in college classes. Backcasting helps students develop essential skills for understanding complex problems, including determining the size of social change necessary to solve a problem, relating the problem under investigation to other problems, and thinking of multiple different potential future trajectories (Quist, Rammelt, Overschie, \& de Werk, 2006). Proponents of backcasting have emphasized how it encourages people to think of the future as something they can shape in a positive direction (Ojala, 2015; Serra Del Pino, 1998). To be maximally beneficial, scholars have stressed that backcasting must allow students the opportunity to express radical viewpoints (Biel, 2014; Ching, 2014; Simpson \& Elias, 2011).

Since teaching methods involving less active student involvement sometimes leave students without essential critical thinking and leadership skills for life after college (Arum \& Roksa, 2010; Carnes, 2014), it is important to investigate active learning activities further in order to improve their usefulness in terms of increasing students' engagement with challenging material and themes. All three of the aforementioned activities - future-oriented discussion, future-oriented roleplay, and backcasting - have the potential to engage students actively such that they have the opportunity to practice valuable skills and achieve critical learning outcomes. To briefly summarize, future-oriented discussion as an activity is typically more openended. In contrast, both backcasting and roleplay are solution-oriented activities, but their intentions differ. In general, a major feature of backcasting is that it initiates student understanding of the multiple potential ways the future could play out (Quist et al., 2006). A major feature of roleplay is that it encourages students to actively engage with each other. Thus, although both backcasting and roleplay can be future-oriented, they can serve different purposes in college classes and support different learning outcomes.

\section{Study Objective and Hypotheses}

In this study, the overall objective was to see how student experiences with future-oriented roleplay and backcasting-two solution-oriented futurology activities - compared to a discussion about the future that was less structured and less focused on a solution. I hypothesized based on prior research on these activities that both a future-oriented roleplaying activity and a backcasting activity would encourage more student interest, student participation, and student understanding than a class discussion. I also further hypothesized, based on prior evidence of the emotional and interpersonal nature of roleplay, that a future-oriented roleplaying activity would encourage more student interest and student participation than a backcasting activity or a discussion. 


\section{Method}

This study was conducted at a large, rural, public university in the United States with approximately 23,000 undergraduates. In compliance with the university's guidelines regarding classroom research, all the study materials were reviewed and approved by the Institutional Review Board (IRB) prior to the implementation of the study. Data were collected in a sociology class, Race and Society, which had 31 enrolled students. Sample sizes for each activity below range from 25 to 27 due to student absence on the day of the activity or non-consent on the survey. Most students in the class were upper-level students, and most were not sociology majors (though most were social science majors). Presumably some of the non-majors took the class to fulfill general education credit. This class met for 50 minutes per session, three days a week.

Three different in-class activities were selected for the focus of this study: (a) a future-oriented discussion, (b) a future-oriented roleplay activity, and (c) a backcasting activity. These activities took place during different class sessions, which involved distinct course topics. All three activities involved approximately 40 minutes of student engagement. During the final 10 minutes of the period, I left the classroom and a representative from the Instructor Support Center distributed and collected surveys, to ensure the anonymity of the data collection process. Each survey had the same format, and they were completely anonymous (no names or other identifying information were collected on the forms). The surveys had four parts.

1. A list of learning outcomes that students could circle if they had practiced that outcome during the activity. Descriptive statistics from this list are in Table 1.

Table 1

Student Perceptions of Skills, Activities, and Concepts Practiced with Discussion, Backcasting, and Roleplay, in percentages

\begin{tabular}{|c|c|c|c|}
\hline & $\begin{array}{l}\text { Discussion } \\
N=25\end{array}$ & $\begin{array}{l}\text { Backcasting } \\
N=27\end{array}$ & $\begin{array}{l}\text { Roleplay } \\
N=26\end{array}$ \\
\hline Understanding general information about (topic) & $96 \%$ & $67 \%$ & $69 \%$ \\
\hline Understanding the complexity of (topic) & $60 \%$ & $44 \%$ & $65 \%$ \\
\hline $\begin{array}{l}\text { Understanding different potential future } \\
\text { trajectories related to (topic) }\end{array}$ & $44 \%$ & $78 \%$ & $54 \%$ \\
\hline Public speaking and related preparation & $28 \%$ & $59 \%$ & $50 \%$ \\
\hline Writing (brainstorming/notes) & $76 \%$ & $70 \%$ & $69 \%$ \\
\hline Writing (more polished) & $12 \%$ & $4 \%$ & $15 \%$ \\
\hline Finding common ground with other people & $56 \%$ & $52 \%$ & $69 \%$ \\
\hline Debating & $12 \%$ & $41 \%$ & $65 \%$ \\
\hline
\end{tabular}


Table 1 Continued

\begin{tabular}{llll}
\hline & $\begin{array}{l}\text { Discussion } \\
\mathrm{N}=25\end{array}$ & $\begin{array}{l}\text { Backcasting } \\
\mathrm{N}=27\end{array}$ & $\begin{array}{l}\text { Roleplay } \\
\mathrm{N}=26\end{array}$ \\
\hline Questioning "common sense" & $20 \%$ & $26 \%$ & $27 \%$ \\
\hline Listening to others & $88 \%$ & $78 \%$ & $81 \%$ \\
\hline Clarifying your own point of view about (topic) & $60 \%$ & $52 \%$ & $42 \%$ \\
\hline Managing emotions constructively & $20 \%$ & $30 \%$ & $38 \%$ \\
\hline $\begin{array}{l}\text { Feeling as if your generation can shape the future } \\
\text { positively }\end{array}$ & $32 \%$ & $63 \%$ & $31 \%$ \\
\hline Using specific evidence to support a conclusion & $56 \%$ & $59 \%$ & $58 \%$ \\
\hline
\end{tabular}

2. Several Likert questions regarding student interest and engagement. Descriptive statistics from these questions are in Table 2.

Table 2

Average Survey Responses to Likert Questions

\begin{tabular}{|c|c|c|c|}
\hline & $\begin{array}{l}\text { Discussion } \\
N=25\end{array}$ & $\begin{array}{l}\text { Backcasting } \\
N=27\end{array}$ & $\begin{array}{l}\text { Roleplay } \\
N=26\end{array}$ \\
\hline $\begin{array}{l}\text { What was your level of interest in (topic) before } \\
\text { today's (activity)? [very low, low, moderate, high, } \\
\text { very high] }\end{array}$ & $2.20(1.12)$ & $2.00(0.68)$ & $2.35(0.89)$ \\
\hline $\begin{array}{l}\text { What was your level of interest in (topic) after } \\
\text { today's (activity)? [very low, low, moderate, high, } \\
\text { very high] }\end{array}$ & $2.96(0.79)$ & $2.63(0.69)$ & $2.65(0.80)$ \\
\hline Pre-post change in interest & $0.76(0.88)$ & $0.63(0.69)$ & $0.31(0.47)$ \\
\hline $\begin{array}{l}\text { To what extent was your group discussion } \\
\text { during this (activity) specific and on topic? [not } \\
\text { at all, a little, somewhat, significantly, extremely] }\end{array}$ & $2.88(0.60)$ & $3.10(0.89)$ & $2.92(0.84)$ \\
\hline $\begin{array}{l}\text { How much did this (activity) increase your } \\
\text { understanding of (topic)? [not at all, a little, } \\
\text { somewhat, significantly, extremely] }\end{array}$ & $2.40(0.96)$ & $2.15(0.99)$ & $2.19(0.94)$ \\
\hline
\end{tabular}

Note. Likert scale was from 0 (very low / not at all) to 4 (very high / extremely). Numbers in parentheses are standard deviations.

3. Two questions that allowed for open-ended written responses. "What, if anything, do you think could have changed about this (activity) that would have made it a more effective learning experience for you?" and "Is there anything else you would like to share about your experience with the (activity) today?" 
4. Instead of a consent form, there was a question at the end of the survey that allowed students to mark yes or no to the question of whether their anonymous responses could be used in a published paper or presentation.

\section{Explanation of the Selected Futurology Activities}

Futurology activities respond to Goggin's (2012) call for active learning opportunities that transition students from being knowledge consumers to knowledge creators. These activities are all feasible in many types of science, social science, or humanities courses with a small to medium number of students, so other instructors could easily adapt the structure to other topics and to other types of courses (introductory or upper-level). Regarding technical math, science, and professional fields, backcasting has been used extensively in sustainability fields (e.g., Ojala, 2015; Quist et al., 2006) and thus can be applied to other technical fields that require project planning.

Descriptions of how the three activities were conducted in the study follow. Futurology classroom activities are tools to be used for instructors' particular pedagogical needs; thus the reason for sharing these descriptions is not to imply that other instructors must or should use these tools as laid out in this study, but instead to give instructors ideas for how to get started using these exercises for their own purposes. The descriptions also provide sufficient background information with which readers can understand the student feedback on these activities that is presented in this study. Instructors can modify these activities to fit the time frame they have available, the topic they are covering, the extent to which they would like to emphasize small-group work or presentation to a large group, or other factors.

\section{Future-Oriented Discussion}

For the discussion, I began by giving an overview of intersectionality, a social science theory of how different social identities (race, gender, social class, etc.) are interconnected. Students had already read and written about this topic for their homework assignment, but this was their first exposure to this theory in the course, so my introductory commentary was necessary to reinforce important themes. I then introduced a short video of a speaker discussing the future of intersectionality (using intersectionality as a strategy for activism). I told the students to focus on how the speaker used intersectionality rather than on their viewpoint on the types of activism featured (e.g., Muslim activism, LGBT activism). The purpose of this video was to give a specific example of how intersectionality can be used to think about mitigating future problems. After the video, students worked in small groups (approximately three people) to reflect orally and in writing on how the speaker used intersectionality and then on how intersectionality can be used to evaluate the future of a modern social problem they are interested in. In order to help students who were new to the topic develop a stronger understanding of this topic, in this discussion, students covered intersectionality in this broad, general way rather than providing specific solutions. After about 10 minutes of group freewriting, the groups spent the next 15 minutes presenting their views to the whole class. 


\section{Future-Oriented Roleplay}

For the roleplay activity, the topic was the future of racially segregated neighborhoods. The class was split into four groups: the Republican Party, Democratic Party, Libertarian party, and Green Party. Students were already familiar with these four American political parties' beliefs from the previous class activity, in which students had been randomly assigned to one of these four viewpoints for a different exercise. In the roleplay activity, students kept the affiliation they had been assigned during this prior activity. In contrast to the intersectionality discussion, which was students' first exposure to the topic during a class session, the fact that students already had some prior exposure to this topic in a previous class session meant that they were prepared to participate in this solution-oriented, future-oriented roleplay about this topic.

Due to random chance, the Republican Party had 10 students; the Democratic Party, 5; the Libertarian Party, 8; and the Green Party, 5. Uneven numbers are more reflective of real political debate than assigning an equal number of people to each category. In this roleplay, students responded as a party to the question of how to increase investment in racially segregated neighborhoods. I gave an overview of how the roleplay would be set up, then handed a worksheet to each group with those same instructions as a reminder.

Each group was given about 12 minutes to pick a primary speaker and

primary notetaker, and then brainstorm both orally and in writing about what kind of legislation their party would support. For the purposes of this roleplay, statements of legislation were a few sentences long and focused on basic ideas about what students wanted the government to do or not do. Then the primary speaker from each party stated their main point of view in one to two minutes; I asked each party one or two clarification questions as they did this. Students expressed the expected viewpoints based on current ideological standpoints known to each party with the only exception being the Libertarians, who were left-leaning. I then constructed an example of "compromise" legislation that included the one idea for legislation all groups indicated support for in their initial statements as well as the one idea for legislation each group thought was most important (which I asked for explicitly). Groups were given a few minutes to speak among themselves, both within their party and to other parties in an attempt to persuade them, and then a vote was taken, in which the Greens, Libertarians, and Democrats voted yes and the Republicans voted no (i.e., the compromise legislation passed).

\section{Backcasting}

I began this activity by explaining backcasting to the students. They were informed that for the purposes of this activity, everyone would be thinking of the midrange future (2030-2050), though backcasting can be used for other time frames as well. The students had read and written on race and transhumanism already in two homework assignments. Again, similar to the future-oriented roleplay, this activity was able to be more solution-oriented because of students' level of prior experience with the topic. I shared with the class what the four main themes people had written about in their homework were and then had them separate into four groups based on 
what theme they wanted to focus on in this activity. I broke up a large group of 12 people into two smaller groups. I handed a worksheet to each group with three steps:

1. Determine a desired future occurrence at a particular year in the future.

2. Work backward to determine what would need to happen between now and that year in order for the occurrence you indicated in Step 1 to come about.

3. Suggest things that could be done in the near future to encourage your desired future outcome.

The students had about 25 minutes to work, and I walked around the room to see how students were doing and answer questions. With the last 10 minutes of the activity, each group stated their desired future outcome and summarized their evaluation of necessary steps to achieve it in one to two minutes.

\section{Results and Discussion}

A summary of student perceptions of skills, activities, and concepts practiced with the three selected activities can be found in Table 1. Means and standard deviations of student responses to Likert questions about interest, on topic discussion, and understanding can be found in Table 2. The paragraphs that follow highlight key findings and themes that emerged from student responses in the surveys that were administered following each of the three activities.

There was considerable variation among the three activities in some of the key learning outcomes. While about two-thirds of students in the future-oriented roleplay and backcasting activity indicated that they learned general information about the day's topic, almost all $(96 \%)$ indicated they did so in the future-oriented discussion. This pattern makes sense because the discussion was more general in nature, while the futureoriented roleplay and backcasting activity were more

Suggest things that could be done in the near future to encourage your desired future outcome. specific and focused on building solutions to known issues. More students (60\% versus $42 \%)$ felt as if discussion helped them clarify their own viewpoint on a topic compared to future-oriented roleplay, which also makes sense, because students were assigned to a viewpoint in the roleplay and were allowed to more freely discuss their own personal views in the discussion activity.

After engaging in the future-oriented roleplay activity, a greater number of students reported that they learned to manage emotions constructively compared to after the discussion (38\% versus $20 \%$ ), which is consistent with the literature (Carnes, 2014; Houle, 2006). In addition, students reported that future-oriented roleplay led to the most debating, which is the primary intent of that activity.

Backcasting was the strongest activity for helping students understand multiple different future trajectories, with $78 \%$ reporting so, in contrast to $44 \%$ for future-oriented discussion and $54 \%$ for future-oriented roleplay. In addition, backcasting encouraged students to feel to the greatest degree (63\%) as if their generation could positively shape the future, which was approximately double that of 
either future-oriented discussion or roleplay. Students expressed intrigue over how futurology can be used to inform action about social issues they care about. As one student wrote, "I never thought about the idea of backcasting, and I think it [is] helpful in potentially solving problems in the future."

Surprisingly, and in contrast to prior research on backcasting (Quist et al., 2006), only $45 \%$ of students in the backcasting activity indicated that they learned about the complexity of the topic, in contrast to about two-thirds of students in the other two activities. Perhaps, as Biel (2014) suggested, the activity did not incorporate enough opportunities to think about radical social or technological change within the next few decades. Students acknowledged the complexity of building ideas and solutions for the future. As one student commented in the backcasting survey, it is difficult to be "specific about including 'future' technology" in an argument.

Another surprising finding was that students' ability to practice public speaking and related preparation in backcasting (59\%) and future-oriented roleplay $(50 \%)$ was approximately double that of discussion $(28 \%)$. This may have been due to students' interpretation of the question, because I explicitly stated at the beginning of the class period during the backcasting and roleplay that small groups would do presentations of their main viewpoints at the end of Students acknowledged the complexity of building ideas and solutions for the future. the period, while I spontaneously decided to have them do so at the end of the discussion period (though the total amount of time for small-group discussion and for presentation was approximately the same among the three activities). Though speculative, it is worth noting that a subtle difference in activity instructions may in part explain the differences students reported in the extent to which they practiced this skill.

Some noteworthy themes also emerged from the open-ended student comments on the three surveys. For instance, four students in the survey about the future-oriented discussion indicated that they would have liked more time for discussion, while only one said so in the survey about backcasting, and none said so in the survey about future-oriented roleplay. Corroborating Roehling et al.'s (2010) point that discussion serves as an opportunity for reflection on diverse ideas, the current study shows that future-oriented discussions are broader than solution-oriented futurology activities. These three activities have different strengths; futu re-oriented discussion can encourage broad thinking, while future-oriented roleplay and backcasting can provide a sense of closure through ending with a vote (in a futureoriented roleplay) or a plan (in a backcasting activity). In classes that have short periods, it may be preferable to limit the number of discussion questions or allow for discussions to span multiple sessions. Large-group discussion in a circle may also contribute to student success and engagement through allowing students to see and hear each other more easily (Wannarka \& Ruhl, 2008). Three students indicated in the comments that they would have liked to incorporate this structure into the futureoriented discussion, and four said they would have liked to incorporate this structure into the future-oriented roleplay.

Many students reported enthusiasm about having a chance to speak to others in class; and, in the case of the future-oriented roleplay and backcasting, where I had students move around the room, they indicated enthusiasm about meeting new people. 
But group work is not without its problems. One student who did not mark that they learned any of the learning objectives in the backcasting survey explained in the comments, "I was in a very unmotivated group; when doing group work, your learning depends a lot on the participation of the other group members!"1 Also, because of this university's location, there is much homogeneity of students' sociopolitical viewpoints, with many having center-left or liberal politic al viewpoints. As such, liberal viewpoints dominated all three activities, and some students holding other viewpoints may have felt as if their thoughts were ignored. For example, as one student wrote in the backcasting survey, "In my [group, who discussed] eugenics, we had a lot of groupthink. But the whole issue on [government] spending is a deeper topic that needs to be exposed." Similarly, some students may have wanted more viewpoints to be represented for the sake of argument; as one student wrote in the roleplay survey, "I would have [liked to have] more polarization of political parties." Instructors who use futurology activities must be creative in order to make activities illustrative of various potential futures. Students in homogeneous classes could be assigned to argue unpopular viewpoints or even assigned to be argumentative or polarized.

Finally, it is worth pointing out that some outcomes did not differ among all three activities. Responses to the Likert scales indicated approximately equal interest in the topics before the activities and approximately equal increases in interest after the activities. Students also reported approximately equal amounts of specific and ontopic discussion, as well as approximately equal increases in understanding of the topics after the activities. Moreover, standard deviations for the Likert measurements ranged from .47 to 1.12, indicating that there was low variability in the Likert responses (i.e., most students responses fell within a point above or below the reported mean). Regarding learning goals, students reported practicing writing, questioning "common sense," listening to others, and using specific evidence to support a conclusion approximately the same amount in all three activities.

\section{Conclusion}

It is valuable for instructors in all disciplines to incorporate futurology into their courses. When students think about the global context, they often worry about negative outcomes (Masini, 2011); futurology activities can help students feel constructive hope through providing an opportunity to counteract worries logically (Ojala, 2015). The three futurology activities included in this study serve different purposes, while achieving similar levels of student engagement and interest. The main

\footnotetext{
${ }^{1}$ Idiosyncratic characteristics may have contributed to some of the motivation or engagement issues noted by some students. I conducted the future-oriented discussion and backcasting during early September, when the non-air-conditioned classroom was warm and humid. In addition, there was also construction and/or yard work occurring outdoors near the classroom during all three activities, and all days the windows were open to allow for air. Any or all of these environmental factors could have contributed to the distraction and disengagement of some students during class.
} 
strength of future-oriented discussion is general understanding of both a topic and one's own perspective on it; of future-oriented roleplay, debate and emotional engagement; and of backcasting, evaluation of different potential futures and a sense of ownership over the future. Instructors must evaluate what their desired learning outcomes are before choosing between futurology activities for their class.

\section{Acknowledgments}

The author would like to acknowledge the support of Sarah Pociask and the rest of the UMass CIRTL (Center for the Integration of Research, Teaching, and Learning) community.

\section{References}

Arum, R., \& Roksa, J. (2010). Academically adrift. Chicago, IL: University of Chicago Press.

Biel, R. (2014). Visioning a sustainable energy future: The case of urban foodgrowing. Theory, Culture \& Society, 31, 183-202. doi: $10.1177 / 0263276414536624$

Carnes, M. C. (2014). From Plato to Erikson: How the war on 'bad play' has impoverished higher education. Arts $\mathcal{E}$ Humanities in Higher Education, 14, 383397. doi: 10.1177/1474022214559846

Ching, Y. (2014). Exploring the impact of role-playing on peer feedback in an online case-based learning activity. The International Review of Research in Open and Distance Learning, 15, 292-311. doi: 10.19173/irrodl.v15i3.1765

Eglitis, D. S., Buntman, F. L., \& Alexander, D. V. (2016). Social issues and problembased learning in sociology: Opportunities and challenges in the undergraduate classroom. Teaching Sociology, 44, 212-220 doi: 10.1177/ $0092055 X 16643572$
Favila, M. (2015). A reflection from the classroom: Teaching students to see from the perspective of the player. The CEA Forum, 44(1), 30-54. Retrieved from http://www.cea-web.org/

Goggin, M. D. (2012). Teaching students to create rather than demonstrate and consume knowledge: A posthuman perspective on rhetorical invention and teaching. InSight: A Journal of Scholarly Teaching, 7, 9-16. Retrieved from http://insightjournal.net/

Houle, A. (2006). Reacting to "reacting." Change: The Magazine of Higher Learning, 38(4), 52-53. Retrieved from http://www.tandfonline.com/toc/vchn20/ current

Lightcap, T. (2009). Creating political order: Maintaining student engagement through "Reacting to the past. PS: Political Science and Politics, 42, 175-179. doi: 10.1017/S1049096509090167

Lloyd, D., \& Wallace, J. (2004). Imagining the future of science education: The case for making futures studies explicit in student learning. Studies in Science Education, 40, 139-178. doi: 10.1080/03057260408560205 
Masini, E. B. (2011). How to teach futures studies: Some experiences. Journal of Futures Studies, 15, 111-120. Retrieved from http://jfsdigital.org/

Miller, C. (2014). Understanding collectivism and female genital cutting through a family role-playing exercise. International Journal of Teaching and Learning in Higher Education, 26, 268-275. Retrieved from http://www.isetl.org/ijtlhe/

Ojala, M. (2015). Hope in the face of climate change: Associations with environmental engagement and student perceptions of teachers' emotion communication style and future orientation. Journal of Environmental Education, 46, 133-148. doi: $10.1080 / 00958964.2015 .1021662$

Quist, J., Rammelt, C., Overschie, M., \& de Werk, G. (2006). Backcasting for sustainability in engineering education: The case of Delft University of Technology. Journal of Cleaner Production, 14, 868-876. doi: 10.1016/j.jclepro.2005.11.032

Roehl, A., Reddy, S. L., \& Shannon, G. J. (2013). The flipped classroom: An opportunity to engage millennial students through active learning techniques. Journal of Family and Consumer Sciences, 105, 44-49. Retrieved from http://www.aafcs.org/Resources/Journal. asp

Roehling, P. V., Kooi, T. L. V., Dykema, S., Quisenberry, B., \& Vandlen, C. (2010). Engaging the millennial generation in class discussions. College Teaching 59, 1-6. doi: 10.1080/87567555.2010.484035
Serra Del Pino, J. (1998). The challenge of teaching futures studies. American Behavioral Scientist, 42, 484-492. doi: 10.1177/0002764298042003020

Simpson, J. M., \& Elias,V. L. (2011). Choices and chances: The sociology roleplaying game-The sociological imagination in practice. Teaching Sociology, 39, 42-56. doi: $10.1177 / 0092055 X 10390646$

Smith, M. K., Wood, W. B., Adams, W. K., Wieman, C., Knight, J. K., Guild, N., \& Su, T. T. (2009). Why peer discussion improves student performance on in-class concept questions. Science, 323, 122-124. doi: 10.1126/science.1165919

Tran, M. V., Weigel, E. G., \& Richmond, G. (2014). Analyzing upper-level undergraduate knowledge of evolutionary processes: Can class discussions help? Journal of College Science Teaching, 43, 87-97. Retrieved from http://www.jstor.org/stable/43633233

Wannarka, R., \& Ruhl, K. (2008). Seating arrangements that promote positive academic and behavioural outcomes: A review of empirical research. Support for Learning, 23, 89-93. doi: 10.1111/j.14679604.2008.00375.x

Witkowski, P., \& Cornell, T. (2015). An investigation into student engagement in higher education classrooms. InSight: A Journal of Scholarly Teaching, 10, 56-67. Retrieved from http://insightjournal.net/ 
Skylar Davidson received an MA in sociology from the University of Massachusetts Amherst in 2016 and is currently completing the PhD program in sociology at that same institution. Skylar has conducted research on incorporating futurology into college teaching in conjunction with the Center for the Integration of Research, Teaching, and Learning (CIRTL) at the University of Massachusetts Amherst. 